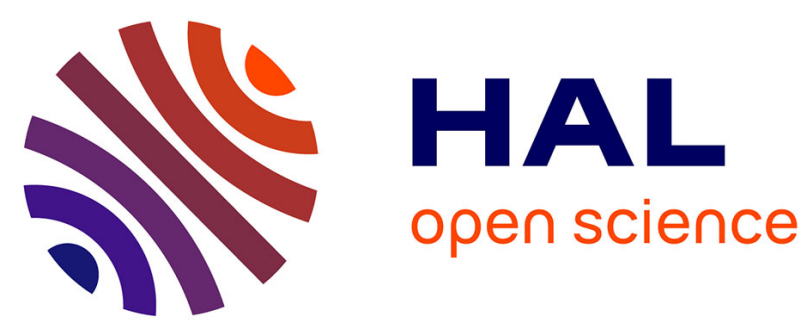

\title{
Antioxidant and anticorrosive properties of oil palm frond lignins extracted with different techniques
}

M. Hazwan Hussin, Affaizza Mohd Shah, Afidah Abdul Rahim, Mohamad Nasir Mohamad Ibrahim, Dominique Perrin, Nicolas Brosse

\section{- To cite this version:}

M. Hazwan Hussin, Affaizza Mohd Shah, Afidah Abdul Rahim, Mohamad Nasir Mohamad Ibrahim, Dominique Perrin, et al.. Antioxidant and anticorrosive properties of oil palm frond lignins extracted with different techniques. Annals of Forest Science, 2015, 72 (1), pp.17-26. 10.1007/s13595-014-04051. hal-01284157

\section{HAL Id: hal-01284157 \\ https://hal.science/hal-01284157}

Submitted on 7 Mar 2016

HAL is a multi-disciplinary open access archive for the deposit and dissemination of scientific research documents, whether they are published or not. The documents may come from teaching and research institutions in France or abroad, or from public or private research centers.
L'archive ouverte pluridisciplinaire HAL, est destinée au dépôt et à la diffusion de documents scientifiques de niveau recherche, publiés ou non, émanant des établissements d'enseignement et de recherche français ou étrangers, des laboratoires publics ou privés. 


\title{
Antioxidant and anticorrosive properties of oil palm frond lignins extracted with different techniques
}

\author{
M. Hazwan Hussin • Affaizza Mohd Shah • Afidah Abdul Rahim • \\ Mohamad Nasir Mohamad Ibrahim • Dominique Perrin • Nicolas Brosse
}

Received: 8 November 2013 / Accepted: 27 June 2014 / Published online: 9 July 2014

(C) INRA and Springer-Verlag France 2014

\begin{abstract}
- Context Oil palm (Elaeis guineensis Jacq.) fronds are produced as waste during the harvest of oil palm fruits. It mainly consists of cellulose, lignin, and hemicelluloses. Lignins like other polyphenols are potent free radical scavengers and are considered to be a valuable source of antioxidant phenolic compounds.

- Aims The aim was to quantify the antioxidant properties of lignins extracted from oil palm biomass using Kraft, soda, and organosolv pulping. The potential of the extracted lignins as inhibitors of mild steel corrosion was also assessed.

- Methods Ground and dried 1-3-mm-mesh-size oil palm fronds were submitted to Kraft, soda, and organosolv pulping in rotary digesters. The extracted lignin was characterized and oxygen uptake was measured. Anticorrosion properties of extracted lignins were monitored via electrochemical measurements and surface analysis.

- Results Soda-extracted lignins displayed the highest antioxidant activities as compared to Kraft and ethanol organosolv lignins. The highest inhibition of corrosion of mild steel was reached in the presence of soda-extracted lignins.

- Conclusion Oil palm fronds are potential sources of lignins usable as green antioxidant for corrosion inhibition of mild steel.
\end{abstract}

Handling Editor: Jean-Michel Leban

M. H. Hussin · A. M. Shah • A. A. Rahim • M. N. M. Ibrahim Lignocellulosic Research Group School of Chemical Sciences, Universiti Sains Malaysia, 11800 Minden, Penang, Malaysia

M. H. Hussin • D. Perrin • N. Brosse ( $₫)$

Laboratoire d'Etude et de Recherche sur le MAteriau Bois

(LERMAB), Faculte des Sciences et Techniques, Universite de Lorraine, Bld des Aiguillettes, Vandoeuvre-les, 54500 Nancy, France

e-mail: nicolas.brosse@lermab.uhp-nancy.fr
Keywords Oil palm fronds · Lignin · Mild steel · Antioxidant $\cdot$ Corrosion inhibitor

\section{Introduction}

Lignin is an aromatic amorphous biopolymer, a binder that holds together the lignocellulosic fibers to ensure rigidity of all vascular plants. It is built up by oxidative coupling of three phenylpropanoid units (trans-p-coumaryl alcohol, transconiferyl alcohol, and trans-sinapyl alcohol) which form a randomized structure in a 3D network inside the cell wall (Ammalahti et al. 1998; Garcia et al. 2009; She et al. 2010). Unlike most natural polymers that consist of a single intermonomeric linkage, lignin is a branched polymer made up of many carbon-to-carbon and ether linkages. The most abundant inter-ether unit linkage in all lignins is the $\beta$-aryl ether bond ( $\beta-\mathrm{O}-4)$. Furthermore, a small proportion of lignin units remains as phenolic, being linked only by $\mathrm{C}-\mathrm{C}$ bonds, such as $\beta-5, \beta-1, \beta-5, \beta-\beta$, and $\alpha-\beta$ linkages. Although this phenolic moiety represents a low and variable fraction of the total lignin, it can strongly affect the reactivity of the polymer (Garcia et al. 2009).

Lignins as well as other polyphenols are potent free radical scavengers and considered to be a valuable source of antioxidant phenolic compounds. One of the analytical methods used to measure the antioxidant capacity is based on the inhibition of the oxidation of organic substrates (Burton et al. 1985; Wanasundara and Shahidi 1994). The oxygen uptake measurement is the most direct method used to measure the reaction extent (Poaty et al. 2010; Saha et al. 2013). Moreover, the induced oxidation of methyl linoleate and its radical long chain reaction is well known to be inhibited by various antioxidants (Uri 1961). The applicability of lignins from different sources as antioxidants has been also successfully tested (Urgatondo et al. 2009). Recent studies by Garcia 
et al. (2010) have revealed that the extraction processes of lignin may give major effect on its antioxidant capacity. The antioxidant properties exhibited from lignin can give broader applications such as antimicrobiology, antiaging, and corrosion inhibitor.

Corrosion affects most of industrial sectors and may cost billions of dollars each year for corrosion prevention and replacement of parts of materials. The use of inhibitors is one of the most effective ways to prevent corrosion. Corrosion inhibitors will reduce the rate of either anodic oxidation or cathodic reduction or both. This will give us anodic, cathodic, or mixed type of inhibition. In an attempt to find corrosion inhibitors which are environmentally safe and readily available, there has been a growing trend in the use of natural products such as leaf or plant extract as corrosion inhibitors for metals in acid cleaning processes. Most of the potential corrosion inhibitors possess an active functional group such as nitro $\left(-\mathrm{NO}_{2}\right)$ and hydroxyl $(-\mathrm{OH})$, heterocyclic compound, and $\pi$ electron (Sastri et al. 2007).

The oil palm fronds (OPF) have been identified as the major contributor of biomass waste in Malaysia. OPF is a lignocellulosic material available at a very low cost which would represent a valuable renewable source of various products and chemicals. Recently, we have demonstrated the potential of lignin obtained from OPF for green material applications (Hussin et al. 2013). In this paper, three different processes were chosen for lignin extraction: Kraft, soda, and aqueous ethanol organosolv processes. The influence of lignin structure by its syringyl (S), guaiacyl (G), and $p$ hydroxyphenyl $(\mathrm{H})$ basic units, phenolic/aliphatic hydroxyl content, and molecular size are also identified via ${ }^{31} \mathrm{P}$ nuclear magnetic resonance (NMR) spectroscopy and gel permeation chromatography (GPC). The antioxidant activities of different types of lignin were also studied using the oxygen uptake index method in the presence of methyl linoleate. The possibility of lignin samples to be applied as corrosion inhibitor was studied. The assessment of the corrosion behavior was studied using potentiodynamic polarization measurement, electrochemical impedance spectroscopy (EIS), and X-ray diffraction (XRD), and the morphology of inhibited mild steel surface was analyzed via scanning electron microscopy (SEM). Next, the inhibition efficiency of lignin samples was correlated with its antioxidant activities.

\section{Materials and method}

The OPF (Elaeis guineensis Jacq.) were obtained from Valdor Palm Oil Mill near Sungai Bakap plantation (Seberang Prai, Malaysia) in mid-2012. The OPF strands were chipped into small pieces. After sun dried for 3 days, the chips were then ground to a $1-3-\mathrm{mm}$ size using Wiley mill, and the fiber was further dried in an oven at $50{ }^{\circ} \mathrm{C}$ for $24 \mathrm{~h}$. The OPF biomass was first subjected to Soxhlet extraction with ethanol/toluene $(2: 1, v / v)$ for $6 \mathrm{~h}$ before use. All chemical reagents used in this study were purchased from Sigma-Aldrich (USA) and VWR (France) and used as received. Dried matter contents were determined using a moisture balance, KERN MRS 120-3 Infra-red moisture analyzer (drying at $105{ }^{\circ} \mathrm{C}$ to constant weight). The effective dry matter content of raw OPF biomass was $\sim 89 \%$. All experiments were run in triplicates, and its average values were represented in the results.

\subsection{Lignin extraction}

Both Kraft and soda pulping processes were carried out in a 10-L rotary digester. All pulping conditions followed the method outlined by Wanrosli et al. (2007) with slight modifications. For Kraft pulping, a $20 \%$ of active alkali and $30 \%$ of sulfidity with water to fiber ratio of 8 was used. The time of maximum cooking temperature $\left(170^{\circ} \mathrm{C}\right)$ was set for $3 \mathrm{~h}$. For soda pulping, $30 \%$ of active alkali alone was applied at the same conditions as described above. The pressure of both Kraft and soda pulping was around $12-15$ bar. The pulp was washed and separated by screening through a sieve and the black liquor was collected. Soda (SL) and Kraft (KL) lignins were precipitated from the concentrated black liquor by acidifying it with $20 \%(v / v)$ sulfuric acid until $\mathrm{pH} 2$ (Mohamad Ibrahim et al. 2011). The precipitated lignins were filtered and washed with water $(\mathrm{pH} 2)$. Both lignins were then dried in an oven at $50{ }^{\circ} \mathrm{C}$ for $48 \mathrm{~h}$. The purification of lignin was conducted by extracting it in the Soxhlet apparatus for $6 \mathrm{~h}$ with $n$ pentane to remove lipophilic non-lignin matters such as wax and lipids. The precipitate was filtered and washed twice with pH 2 water to remove the excess $n$-pentane and non-lignin phenolic compounds which may remain after the pulping process. The purified KL and SL were then dried in an oven for another $48 \mathrm{~h}$.

For organosolv pulping process, the OPF were treated with aqueous ethanol $(35 / 65, v / v)$ with $0.5 \%(w / w)$ sulfuric acid as a catalyst at $190{ }^{\circ} \mathrm{C}$ for $60 \mathrm{~min}$ (El Hage et al. 2009). The material-to-liquid ratio used was 1:8. After the reactor was loaded with OPF and cooking liquor, it was heated to the operating temperature which was then maintained throughout the experiment (pressure around 25 bar). After the treatment, the pre-treated OPF was filtered and washed with warm aqueous ethanol $(8: 1,3 \times 50 \mathrm{~mL})$. The liquor was diluted with three volumes of water to precipitate the ethanol organosolv lignin (EOL), and the precipitate was then collected by centrifugation at 3,500 rpm for $10 \mathrm{~min}$. The resulting EOL was dried in an oven at $50{ }^{\circ} \mathrm{C}$ for $48 \mathrm{~h}$.

\subsection{Characterization of lignin}

All NMR spectroscopy experiments were performed on a Bruker Avance 300 spectrometer operating at a frequency of 
$100.59 \mathrm{MHz} .{ }^{31} \mathrm{P}$ NMR spectra were acquired after derivatizing 25-mg lignin with 2-chloro-4,4,5,5-tetramethyl1,1,3,2-dioxaphospholane (TMDP) as previously described by Granata and Argyropoulos (1995).

Lignin samples were subjected to acetylation in order to enhance their solubility in organic solvents used in GPC. The number average molecular weights $\left(M_{\mathrm{n}}\right)$ and weight $\left(M_{\mathrm{w}}\right)$ of lignin and cellulose were determined after derivatization by GPC with a Dionex Ultimate 3000 HPLC system consisting of an autosampler and a UV detector and using tetrahydrofuran as eluent. Standard polystyrene samples were used to construct a calibration curve. Data were collected and analyzed with Chromeleon software version 6.8 (Dionex Corp., USA).

2.3 Measurement of lignin antioxidant activity by oxygen uptake method

Antioxidant properties of lignins were investigated by evaluating oxygen uptake inhibition during oxidation of methyl linoleate. The induced oxidation by molecular oxygen was performed in a gas-tight borosilicate glass apparatus (El Oualja et al. 1995). Butanol was used as solvent; it is a reference solvent of different studies on natural antioxidant in our apparatus; the solvent should not be oxidized and its vapor pressure must be low enough. Temperature was set to $60{ }^{\circ} \mathrm{C}$, and initial conditions inside the vessel were as follows: methyl linoleate (Fluka, $99 \%$ ) concentration $0.32 \mathrm{~mol} \mathrm{~L}^{-1}$; 2,2'-azobisisobutyronitrile (AIBN) (Fluka, $98 \%$ ) concentration $7.2 \times 10^{-3} \mathrm{~mol} \mathrm{~L}^{-1}$; lignin concentration $0.2 \mathrm{~g} \mathrm{~L}^{-1}$; and oxygen pressure 150 Torr. As the intensity of oxygen bubbling in the reaction media has no influence on the oxidation, dissolution of oxygen in not a limiting step. Through lignins are soluble in butanol at $60{ }^{\circ} \mathrm{C}$, they are fairly soluble at room temperature so that we have used methanol lignin solution. Methanol was evaporated before reaction.

Oxygen uptake was monitored continuously by a pressure transducer (Viatron model 104). Without any additive, oxygen uptake is roughly linear and constitutes the control. In the presence of an antioxidant, oxygen consumption is slower, and the oxygen uptake inhibition (OUI) of extract was estimated by comparing oxygen uptake at a chosen time $(3 \mathrm{~h})$, in the presence of this compound (pressure variation $\Delta \mathrm{P}_{\text {sample}}$ ) and in the absence of the compound $\left(\Delta \mathrm{P}_{\text {control }}\right)$ according to:

OUI $(\%)=\left(\Delta P_{\text {control }}-\Delta P_{\text {sample }}\right) / \Delta P_{\text {control }} \times 100$

This ratio defines antioxidative capacity as an OUI; it should spread from 0 to $100 \%$, for poor and strong antioxidants, respectively, and may be negative for prooxidants.

\subsection{Preparation of specimens and electrolytes}

Mild steel coupons having chemical composition (wt $\%$ ) of 0.08 C, 0.01 Si, 1.26 Mn, 0.02 P, and remaining Fe were used. The specimens were polished successively using 400, 600, and 800 gritted emery papers. Next, they were degreased with methanol and washed with distilled water before and after each experiment.

The solutions were prepared using AR grade hydrochloric acid. Appropriate concentrations of acids were prepared by using distilled water. The lignin samples were first dissolved in a small volume of methanol and sonicated to increase solubility. The dissolved lignin samples were next diluted with $0.5 \mathrm{M} \mathrm{HCl}$. The concentration of inhibitor at $500 \mathrm{ppm}$ was prepared by diluting the stock lignin solution.

\subsection{Electrochemical measurements}

A three-electrode cell assembly consists of a mild steel coupon $(9 \mathrm{~cm} \times 3 \mathrm{~cm} \times 0.1 \mathrm{~cm}$ dimension with an exposure surface of $3.124 \mathrm{~cm}^{2}$ ) as a working electrode (WE), platinum rod as a counter electrode (CE), and saturated calomel electrode (SCE) as a reference electrode (RE) containing $100 \mathrm{~mL}$ of electrolyte. The temperature of the electrolyte was maintained at room temperature $\left(28 \pm 2{ }^{\circ} \mathrm{C}\right)$.

The EIS, was carried out using Gamry Reference 600 after the open circuit potential, $E_{\text {ocp }}$, has stabilized (30 min) over a frequency range of $100 \mathrm{kHz}$ to $0.1 \mathrm{~Hz}$ with a signal amplitude perturbation of $5 \mathrm{mV}$ and scan rate of $1 \mathrm{mV} \mathrm{s}^{-1}$. Next, it was fitted with several sets of circuits using ZSim Demo software to obtain the charge transfer resistance, $R_{\mathrm{ct}}$ values. The inhibition efficiency (IE\%) was calculated by the following equations:

$\mathrm{IE} \%=\left(1-\frac{R_{\mathrm{ct}}}{R_{\mathrm{ct}}^{\prime}}\right) \times 100$

where $R_{\mathrm{ct}}$ and $R_{\mathrm{ct}}^{\prime}$ are referred to charge transfer resistance without and with addition of inhibitor (lignin), respectively.

Potentiodynamic polarization studies were carried out without and with addition of lignin solution (500 ppm) in $0.5 \mathrm{M} \mathrm{HCl}$ solutions at a scan rate of $1 \mathrm{mV} \mathrm{s}^{-1}$. The $E_{\text {ocp }}$ was measured for 30 min to allow stabilization of the steadystate potential. The potential range was calculated from the $E_{\text {ocp }}$ values obtained $( \pm 250 \mathrm{mV})$. The percentage of IE\% was calculated by using the following equation:

$\mathrm{IE} \%=\frac{I_{\text {corr }}-I_{\text {corr }(i)}}{I_{\text {corr }}} \times 100$

where $I_{\text {corr }}$ and $I_{\text {corr (i) }}$ are referred to corrosion current density without and with addition of inhibitor (lignin), respectively. Potentiodynamic polarization curves were produced using Echem Analyst software. 


\subsection{Surface and rust transformation analyses}

The nature of the film formed on the surface of the metal specimens was evaluated by SEM analysis (Leo Supra 50VP). Corrosion-inhibited and blank (without inhibitor) specimens from the electrochemical measurement were examined. Prerusted samples were prepared by subjecting the mild steel plates to the salt spray chamber according to the American Society for Testing and Materials ASTM B 117 (6 h exposure in $5 \%(w / v) ~ \mathrm{NaCl}$ at $98 \%$ humidity, $1.0 \mathrm{~mL} \mathrm{~h}^{-1}$ spray rate, $1.0 \mathrm{~kg} \mathrm{~cm}^{-3}$ of pressure and followed by drying in an oven at $40^{\circ} \mathrm{C}$ ) (ASTM 1973). The pre-rusted plates were immersed in $1 \mathrm{~g} \mathrm{~L}^{-1}$ lignin in methanol solution for $24 \mathrm{~h}$. The changes in the rust structures were observed from XRD patterns (PANalytical X'Pert PRO MRD PW3040).

\section{Results}

\subsection{Characterization of lignin}

Higher yield of Kraft (KL 18.29 \%) and soda (SL $15.86 \%$ ) and lower yield of EOL (9.26 \%) lignins were observed after delignification process which indicates that alkaline process accelerates the removal of lignin from OPF biomass. Data from the quantitative ${ }^{31} \mathrm{P}$ NMR of the three lignin samples (Fig. 1), obtained following their derivatization with TMDP, are presented in Table 1. The concentration of each hydroxyl functional group (in mmol g${ }^{-1}$ ) was calculated on the basis of the hydroxyl content of the internal standard cyclohexanol and its integrated peak area (Granata and Argyropoulos 1995). According to this data, it can be observed that alkaline lignins (KL and SL) gave lower concentration of aliphatic $-\mathrm{OH}$ groups and higher concentrations of phenolic - $\mathrm{OH}$ groups compared to EOL. The weight average $\left(M_{\mathrm{w}}\right)$ and number average $\left(M_{\mathrm{n}}\right)$ molecular weight of all lignins were computed from their chromatograms. From the results, it can be seen that the weight average $\left(M_{\mathrm{w}}\right)$ of SL $\left(1,660 \mathrm{~g} \mathrm{~mol}^{-1}\right)$ and EOL $\left(1,215 \mathrm{~g} \mathrm{~mol}^{-1}\right)$ lignin was lower than KL $\left(2,063 \mathrm{~g} \mathrm{~mol}^{-1}\right)$ lignin.

\subsection{Antioxidant activity by oxygen uptake}

In this study, we have determined the antioxidant activity of lignin by employing oxygen uptake inhibition method. Unlike antiradical tests broadly used in the literature (e.g., di(phenyl)-(2,4,6-trinitrophenyl)iminoazanium (DPPH), ABTS), the oxygen uptake inhibition is a realistic model of autoxidation reactions taking place in food and living systems, even though substrates more complex than methyl linoleate are more representative of specific situations. In addition, previous studies done by Poaty et al. (2010) and Saha et al.
(2013) have revealed that the inhibition obtained by oxygen uptake test shows similar trend to that of DPPH assay. The oxygen uptake profile during autoxidation of methyl linoleate is shown in Fig. 2. By comparing the linear curve of methyl linoleate alone (control), it appears that all lignin samples exhibited antioxidant activity by slowing down the oxidation of methyl linoleate. In order to correlate our observation with the previous finding by El Hage et al. (with regards to structure, molecular weight, and phenolic $-\mathrm{OH}$ content), butanol has been chosen as the corresponding solvent to dissolve lignin samples. SL gives highest inhibition (OUI $=74 \%)$ followed by EOL (OUI=60 \%) and KL (OUI=55 \%).

\subsection{Electrochemical impedance spectroscopy measurement}

The corrosion of mild steel in $0.5 \mathrm{M} \mathrm{HCl}$ solution in the presence of lignin samples was investigated by EIS at room temperature after an exposure period of $30 \mathrm{~min}$. Nyquist plots for mild steel obtained at the interface in the absence and presence of lignins at constant concentration (500 ppm) are given in Fig. 3. The impedance diagram obtained with $0.5 \mathrm{M}$ $\mathrm{HCl}$ shows only one depressed capacitive loop at the higher frequency range. The same trend was also noticed for mild steel immersed in $0.5 \mathrm{M} \mathrm{HCl}$ containing KL, SL, and EOL. Table 2 lists the impedance parameters of the Nyquist plots of the lignin extractives at the concentration of $500 \mathrm{ppm}$. The EIS measurement reveals that at the concentration of $500 \mathrm{ppm}$, the percentage of inhibition efficiency of lignin is highest for SL $\left(\mathrm{IE}_{\mathrm{soda}}=85.81 \%\right)$ and followed by EOL $\left(\mathrm{IE}_{\text {organosolv }}=\right.$ $81.84 \%)$ and $\mathrm{KL}\left(\mathrm{IE}_{\mathrm{Kraft}}=67.85 \%\right)$ lignin.

\subsection{Potentiodynamic polarization measurement}

Figure 4 represents the anodic and cathodic Tafel polarization curves of mild steel at $500 \mathrm{ppm}$ of lignins in $0.5 \mathrm{M} \mathrm{HCl}$. The inhibition efficiency of lignin at the concentration of $500 \mathrm{ppm}$ is given in the following order: $\mathrm{IE}_{\text {soda }}=98.67 \%>\mathrm{IE}_{\text {organosolv }}=$ $97.21>\mathrm{IE}_{\mathrm{Kraft}}=85.89 \%$. Lower current density values $\left(\mathrm{I}_{\text {corr }}\right.$ Kraft $0.1580 \mathrm{~mA} \mathrm{~cm}^{-2} ; \mathrm{I}_{\text {corr soda }} 0.0146 \mathrm{~mA} \mathrm{~cm}^{-2} ; \mathrm{I}_{\text {corr organosolv }}$ $0.0312 \mathrm{~mA} \mathrm{~cm}^{-2}$ ) of lignin samples than blank solution ( $\mathrm{I}_{\text {corr }}$ blank $1.12 \mathrm{~mA} \mathrm{~cm}^{-2}$ ) were observed.

\subsection{Surface and rust transformation analysis}

Surface analysis using SEM proved a significant improvement on the surface morphology of mild steel plates in the presence of SL. From Fig. 5a, a rough surface was noticed for mild steel immersed in $0.5 \mathrm{M} \mathrm{HCl}$ solution. On the other hand, a smooth surface was observed on the inhibited mild steel surface (Fig. 5b). XRD pattern (Fig. 6) of the pre-rusted plate shows that lepidocrocite $(\mathrm{L}: \gamma$-FeOOH$)$ and magnetite $\left(\mathrm{M}: ~ \mathrm{Fe}_{3} \mathrm{O}_{4}\right)$ were the main components present, with traces of goethite (G: $\alpha$-FeOOH). Upon immersion in the SL solutions, several 


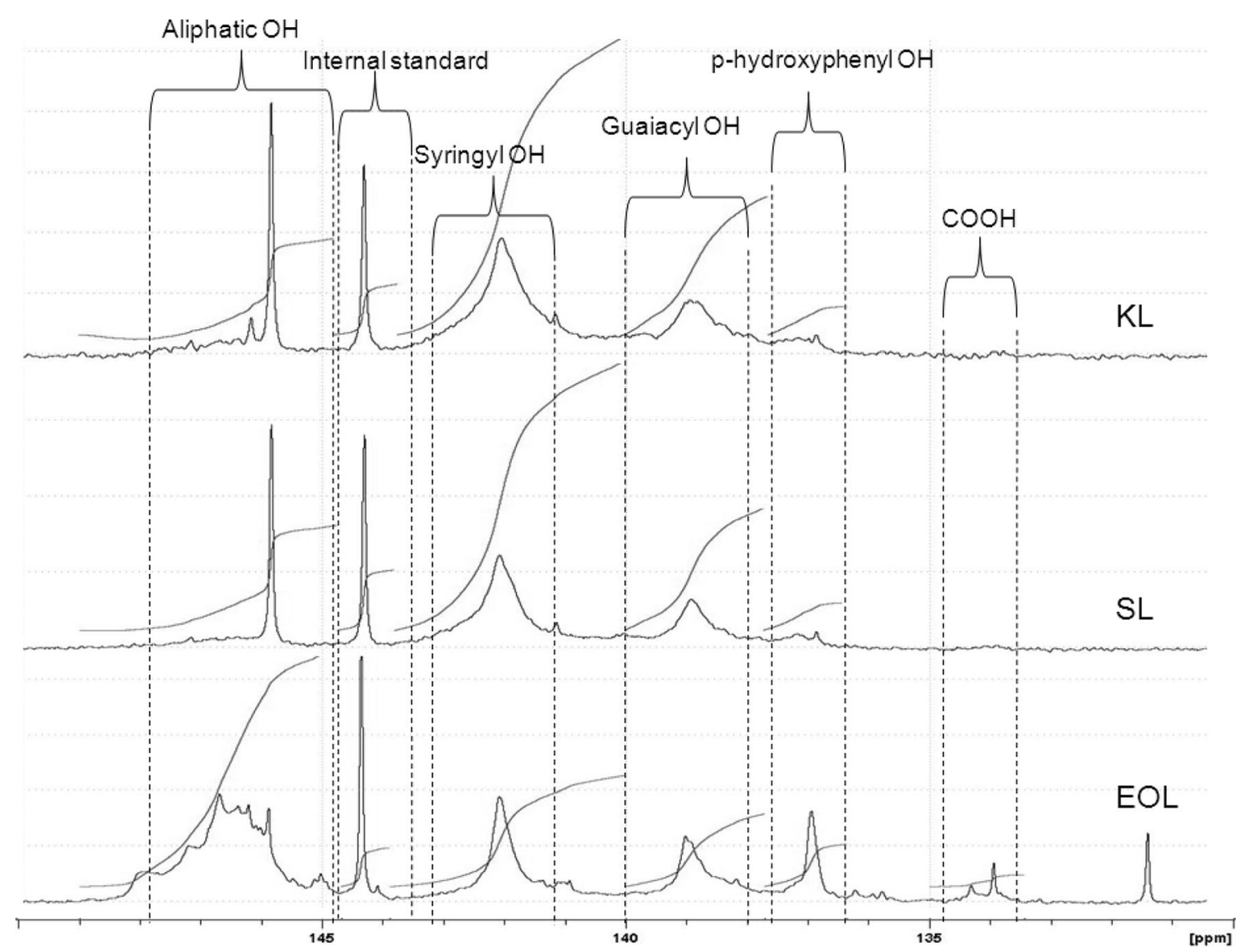

Fig. $1{ }^{31} \mathrm{P}$ NMR spectrum of $\operatorname{Kraft}(K L)$, soda $(S L)$, and ethanol organosolv lignin $(E O L)$

lepidocrocite peaks diminished as well as reduced in favor of formation ferric-lignates, thus impeding further corrosion process.

\section{Discussion}

\subsection{Characteristic of lignin}

The lower yield of lignin after ethanol organosolv process was perhaps due to (i) low severity reaction conditions used and

Table 1 Lignins characterized by ${ }^{31} \mathrm{P}$ NMR

\begin{tabular}{lllll}
\hline ppm & Assignments ( ${ }^{31} \mathrm{P}$ NMR $)$ & \multicolumn{3}{l}{$\mathrm{mmol}^{-1}$} \\
\cline { 3 - 5 } & & $\mathrm{KL}$ & $\mathrm{SL}$ & $\mathrm{EOL}$ \\
\hline $150-145$ & Aliphatic $-\mathrm{OH}$ & 0.45 & 0.42 & 1.49 \\
144.8 & Cyclohexanol (internal standard) & & & \\
$144-140$ & Syringyl -OH & 1.42 & 1.07 & 0.69 \\
$140-138$ & Guaiacyl -OH & 0.65 & 0.48 & 0.45 \\
$138-136$ & $p$-Hydroxyphenyl $-\mathrm{OH}$ & 0.13 & 0.11 & 0.26 \\
$135-133$ & Carboxylic acid & - & - & 0.07 \\
\hline
\end{tabular}

(ii) the effect of aqueous ethanol solvent which dissolves small molecular weight of lignin (El Hage et al. 2010; Hussin et al. 2013). The degree of delignification of OPF lignin can be possibly increased by using alkaline pulping method as reported previously by Hussin et al. (2013). In addition, EOL yield can be improved by changing the severity factor of organosolv pulping (changing of temperature, extraction time, percentage of acid, and solvent ratios). The extraction of lignin via different pulping process will produce different composition and structures. This can be evidenced through the $\mathrm{S}$ and $\mathrm{G}$ content, hydroxyl content, and molecular weight values obtained from ${ }^{31} \mathrm{P}$ NMR and GPC analysis.

In the ${ }^{31} \mathrm{P}$ NMR studies, the amount of hydroxyl groups based on the integration was calculated in the phosphorylated lignin samples. It was observed that the amount of aliphatic $\mathrm{OH}$ from EOL is slightly higher compared to $\mathrm{KL}$ and SL which justify the presence of more aliphatic $-\mathrm{OH}$ functional groups in EOL structure. This phenomenon is mainly due to the extensive depolymerization of lignin during alkaline pulping through the scission of $\beta-\mathrm{O}-4$ bonds leading to the production of phenolic -OH groups (Hussin et al. 2013). In addition, the reduction of aliphatic $-\mathrm{OH}$ is probably due to the dehydration reactions through acid-catalyzed elimination reaction (El Hage et al. 2009; Obama et al. 2012). Higher content of phenolic $-\mathrm{OH}$ is indeed beneficial for later 
Fig. 2 Oxygen uptake profile (oxygen pressure variation, $\mathrm{PO}_{2}$ in Torrs vs time in hours) of Kraft $(K L)$, soda $(S L)$, and ethanol organosolv lignin $(E O L)$

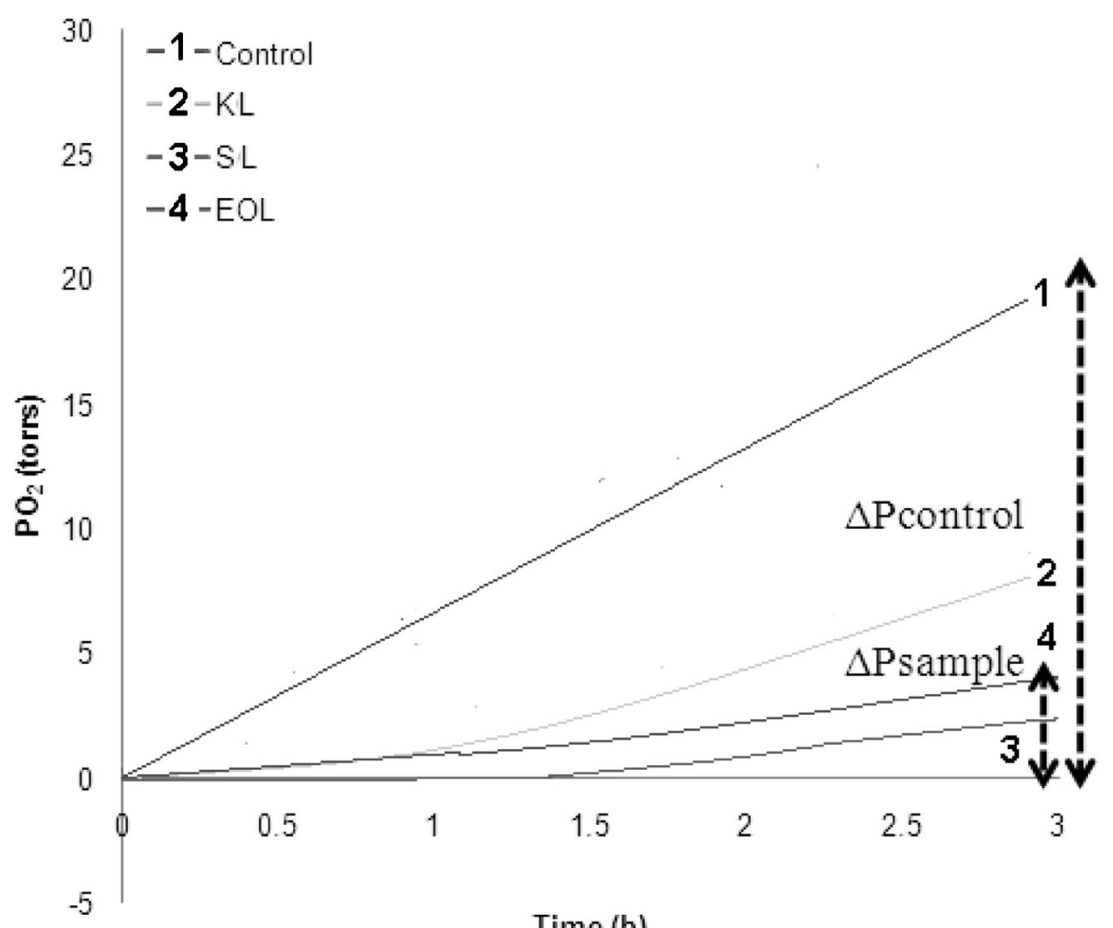

Time (h) applications especially antioxidant activity and corrosion inhibition. In addition, all lignin samples show a small value for $\mathrm{G}$ unit and higher $\mathrm{S}$ unit. Higher signals for $\mathrm{S}$ unit in all OPF lignin may suggest that both alkaline and organosolv processes will produce lignins that contain more syringal basic unit than guaiacyl unit.
GPC analyses have shown that weight average $\left(M_{\mathrm{w}}\right)$ of SL $\left(1,660 \mathrm{~g} \mathrm{~mol}^{-1}\right)$ and EOL $\left(1,215 \mathrm{~g} \mathrm{~mol}^{-1}\right)$ lignin was lower than $\mathrm{KL}\left(2,063 \mathrm{~g} \mathrm{~mol}^{-1}\right)$ lignin. This phenomenon can be explained according to the different lignin composition. Even though $\beta$-O4 is the most common linkage in all lignin types, there are also some quantities of $\mathrm{C}-\mathrm{C}$ bonds between the phenylpropanoic

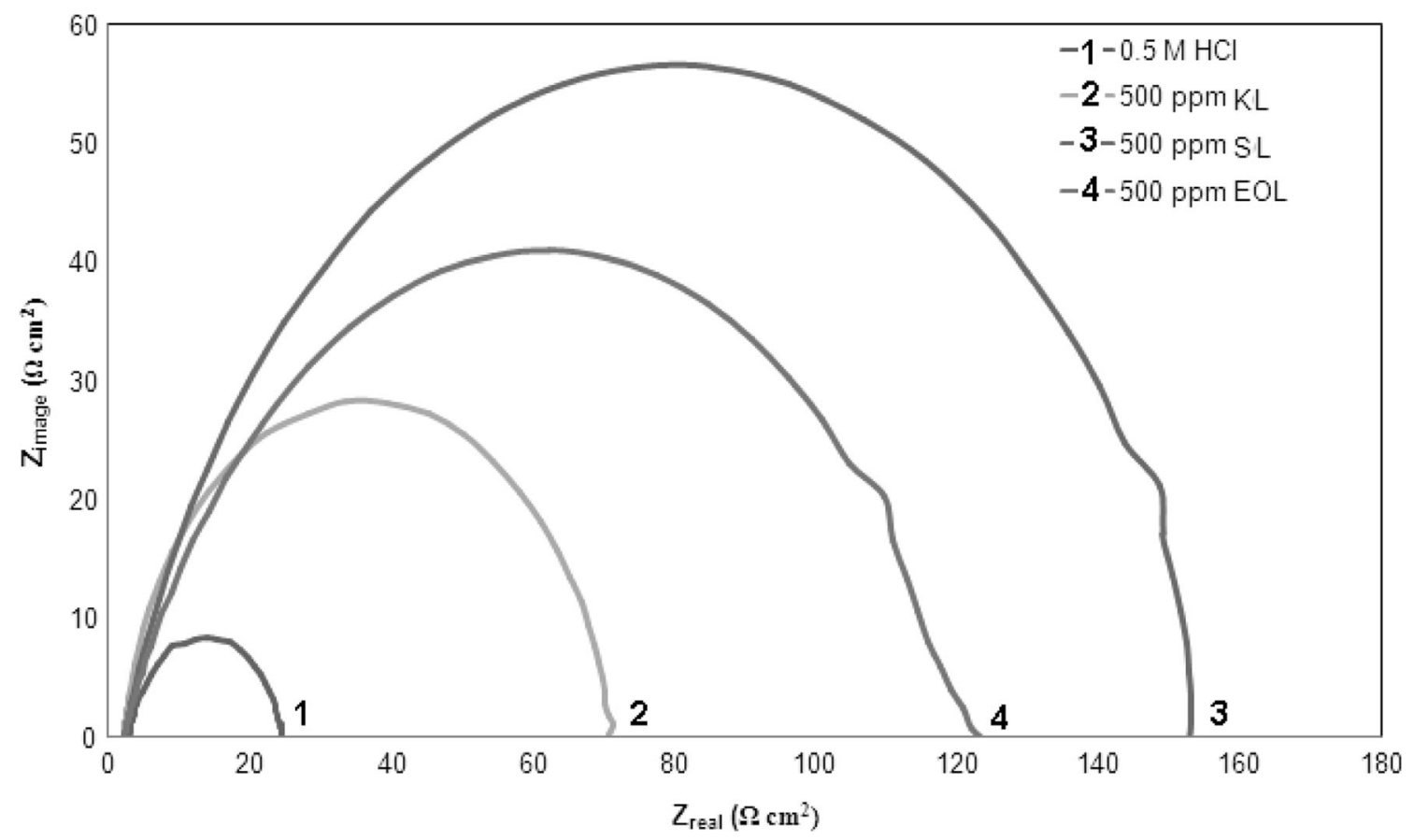

Fig. 3 Nyquist plot (imaginary impedance, $Z_{\text {image }}$ in $\Omega \mathrm{cm}^{2}$ vs real impedance, $Z_{\text {real }}$ in $\Omega \mathrm{cm}^{2}$ ) of mild steel in $0.5 \mathrm{M} \mathrm{HCl}$ solution in the absence and presence of Kraft $(K L)$, soda $(S L)$, and ethanol organosolv lignin $(E O L)$ 
Table 2 Impedance parameters and inhibition efficiency of mild steel in $0.5 \mathrm{M} \mathrm{HCl}$ solutions containing 500-ppm lignin solutions

\begin{tabular}{lllll}
\hline Samples & $R_{\mathrm{ct}}\left(\Omega \mathrm{cm}^{2}\right)$ & $R_{\mathrm{s}}\left(\Omega \mathrm{cm}^{2}\right)$ & Number & IE\% \\
\hline $0.5 \mathrm{M} \mathrm{HCl}$ & 68.41 & 8.89 & 0.84 & - \\
$500 \mathrm{ppm} \mathrm{KL}$ & 212.8 & 6.93 & 0.91 & 67.85 \\
$500 \mathrm{ppm} \mathrm{SL}$ & 482.0 & 7.38 & 0.80 & 85.81 \\
$500 \mathrm{ppm} \mathrm{EOL}$ & 376.8 & 6.98 & 0.76 & 81.84 \\
\hline
\end{tabular}

units (which involve C5 of aromatic ring). According to Van de Klashorst (1989), under alkaline conditions, some $\alpha$-hydroxyl groups from quinone methide intermediates form the alkalistable methylene linkages after it reacted with other lignin fragments. Due to the more severe conditions used in Kraft pulping, high value of lignin molecular weight can be observed. On top of that, previous studies have shown that organosolv pulping process can promote the fragmentation of small molecular weight lignin (El Hage et al. 2010). Meanwhile, low $M_{\mathrm{n}}$ value for SL is due to the soda pulping process. In this process, the hydroxide ions react with the lignin causing the fragmentation of polymer in the water/alkali soluble fragment. This corroborates that the cleavage of $\alpha$ and $\beta-\mathrm{O}-4$ is the predominant process in alkaline medium (Hussin et al. 2013). Low polydispersity of EOL $\left(M_{\mathrm{w}} / M_{\mathrm{n}}=1.17, M_{\mathrm{n}}=1,036\right)$ compared to KL $\left(M_{\mathrm{w}} / M_{\mathrm{n}}=1.89, M_{\mathrm{n}}=1,063\right)$ and SL $\left(M_{\mathrm{w}} / M_{\mathrm{n}}=2.33, M_{\mathrm{n}}=713\right)$ indicated the uniformity of overall packing structures of lignin.
Besides the severe condition, the molecular weight of lignins was also affected by its $\mathrm{S}$ and $\mathrm{G}$ content. As $\beta-\mathrm{O}-4$ is the most common linkage in lignin, small quantities of $\mathrm{C}-\mathrm{C}$ bonds between the phenylpropanoic units which involve $\mathrm{C} 5$ of aromatic ring may also be present. Guaiacyl-type units are capable of forming this kind of bond, but this is not possible in syringyl-type units as it has both $\mathrm{C} 3$ and $\mathrm{C} 5$ positions substituted by methoxy groups. As a result, these $\mathrm{C}-\mathrm{C}$ bonds are not cleaved during the pulping process due to its high stability. Hence, the lignin that contains slightly high guaiacyltype units is expected to show high molecular weight (HMW) than those having high contents of syringyl-type units (Tejado et al. 2007; Hussin et al. 2013).

\subsection{Antioxidant activity of lignin and its correlation to anticorrosion properties}

Lignin has been identified as potent free radical scavenger and considered to be a valuable source of antioxidant phenolic compounds. The antioxidant activity determined by oxygen uptake test has revealed that SL has higher tendency to reduce the evolution of oxygen gas as compared to KL and EOL. It is believed that the small molecular weight and high phenolic $\mathrm{OH}$ content of SL and EOL affect the performance of the antioxidant activity. The antioxidant efficiency of lignin has been described to be related with their structure, purity, and

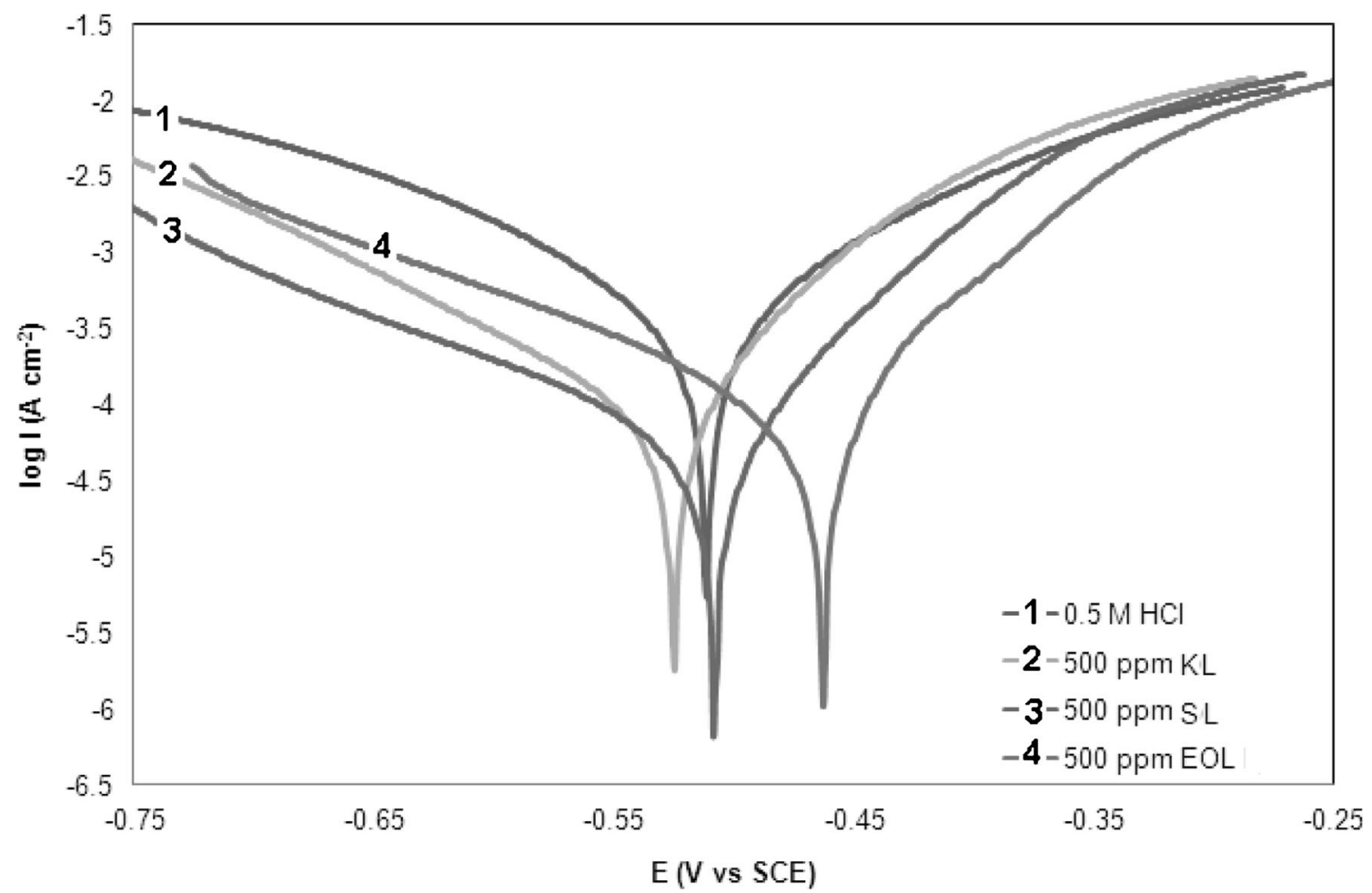

Fig. 4 Tafel curve (corrosion current density, $I$ in $\mathrm{A} \mathrm{cm}^{-2}$ vs corrosion potential, $E$ in V vs SCE) of mild steel in $0.5 \mathrm{M} \mathrm{HCl}$ solution in the absence and presence of $\operatorname{Kraft}(K L)$, soda $(S L)$, and ethanol organosolv lignin $(E O L)$ 
Fig. 5 Scanning electron microscope (SEM) micrographs of a mild steel without inhibitor, $0.5 \mathrm{M} \mathrm{HCl}$, and $\mathbf{b}$ mild steel with soda lignin, $500 \mathrm{ppm}$, at magnification of $\times 100$
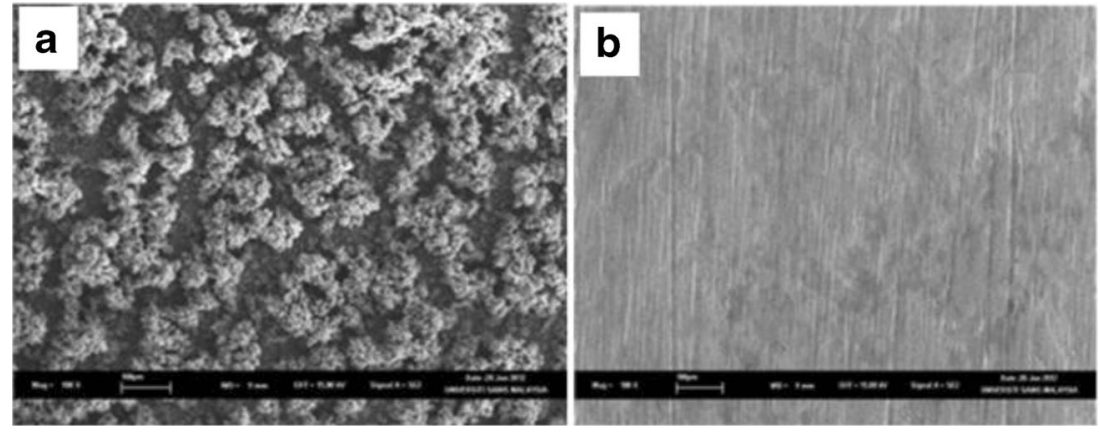

polydispersity (Pouteau et al. 2003; Pan et al. 2006). Lignin with high molecular weight, low phenolic - $\mathrm{OH}$ content, and polydispersity value tends to experience poor antioxidant activity (El Hage et al. 2012) as observed in KL. Nevertheless, this result is effective only for antioxidant activity of lignin in butanol, and since alkaline lignins (KL and SL) do not completely dissolve in butanol, the results sometimes could vary.

A positive correlation between the antioxidant and anticorrosion properties has been obtained in this study. In the EIS study, the $R_{\mathrm{ct}}$ represents the charge transfer resistance whose value is a measure of electron transfer across the surface and is inversely proportional to corrosion rate (Abdel-Gaber et al. 2006). The constant phase element (CPE) is introduced in the circuit instead of a pure double-layer capacitor to give a more accurate fit (Hussin and Kassim 2011). The diameter of Nyquist plots increased on addition of lignins which suggested that inhibitive film was formed that increased the resistivity of the mild steel surface. The high frequency (HF) loops have depressed semicircular appearance, $0.5 \leq n \leq 1$, which is often referred to as frequency dispersion as a result of the inhomogeneity (Boomersbach et al. 2005) or the roughness (Benedeti et al. 1995) of the solid surface.
Meanwhile, polarization measurements have shown that the decrease of current density values was due to the adsorption of the inhibitor on mild steel/acid solution interface (Ahamad et al. 2010). Here, the decrease of current density of lignins in comparison with $0.5 \mathrm{M} \mathrm{HCl}$ (blank) for both anodic and cathodic sites may suggest the mixed type of corrosion inhibition behavior. A study of corrosion prevention and protection has supported that mixed type of inhibitors is generally represented by organic compounds with donor atoms $\mathrm{Se}, \mathrm{S}, \mathrm{N}$, or $\mathrm{O}$ instead of having reactive functional groups which latch on to the metal (Sastri et al. 2007; Hussin and Kassim 2011). Thus, the presence of $\mathrm{S}$ and $\mathrm{O}$ heteroatoms in $\mathrm{KL}, \mathrm{SL}$, and EOL lignin structure may have an important role on the corrosion inhibition of mild steel. Both EIS and polarization studies have revealed that the highest corrosion inhibition was obtained with SL, and this is in a good agreement with the antioxidant studies where SL gave the highest OUI value compared to KL and EOL.

Both EIS and polarization measurements have revealed that SL gave the highest percentage of IE\% than to KL and EOL. Hence, this clearly shows that SL will give better antioxidant and corrosion inhibition properties than KL and EOL lignin. It was believed that during soda pulping,
Fig. 6 X-Ray diffraction (XRD) patterns of pre-rusted samples (blank) and those treated with soda lignin $(S L)$

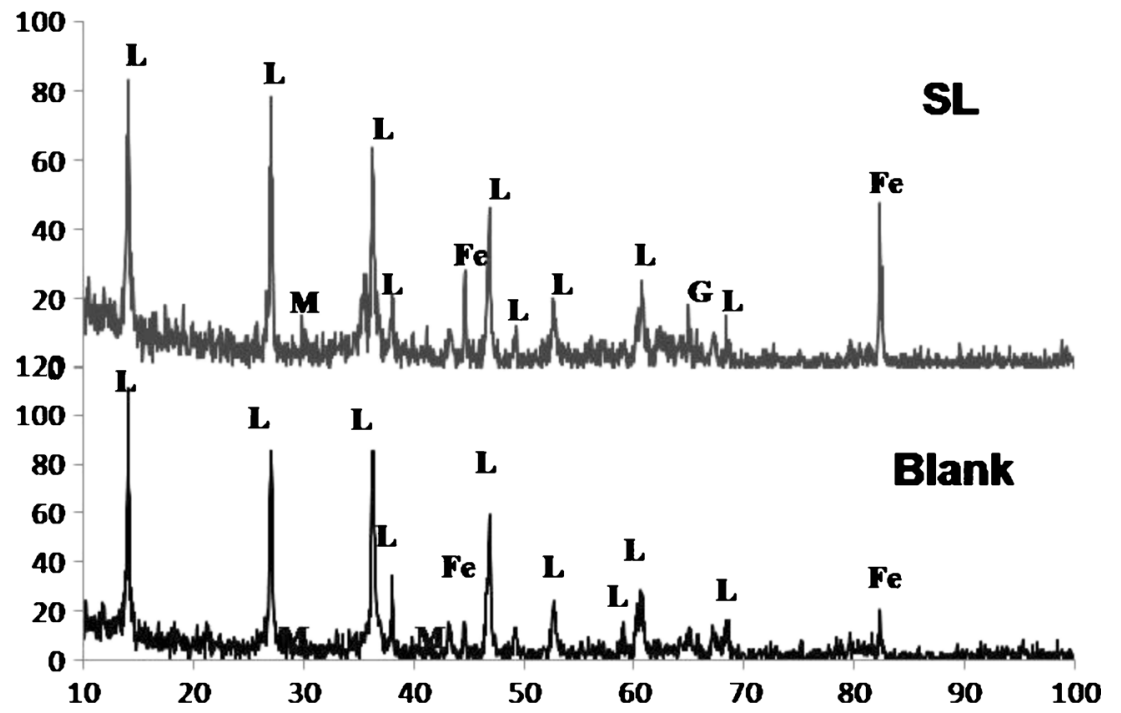


extensive depolymerization of lignin has occurred through the scission of $\beta-\mathrm{O}-4$ bonds leading to the production of phenolic $-\mathrm{OH}$ groups. Meanwhile, higher phenolic $-\mathrm{OH}$ content and low molecular weight of SL show better antioxidant activity and anticorrosion properties than KL and EOL. It is suggested that the corrosion inhibition of mild steel in the presence of lignin extract occurs through the interaction between the electron-donating atoms of oxygen and sulfur with the metal ion surface. On top of that, the phase transformation of corrosion products upon the immersion in the SL solutions has reduced several lepidocrocite peaks. Perhaps, the formation ferric-lignates will slow down further oxidation process of iron metal into other corrosion products. Better corrosion inhibition properties exhibited by the lignin extracts give new alternative way for the sustainability of green material applications.

\section{Conclusion}

In this work, the treatment of OPF with alkaline and organic alcohol solution is practically suitable for the isolation of lignins. The differences in the spectral characteristics and analytical results among the lignin samples are related to the delignification process. ${ }^{31} \mathrm{P}$ NMR spectra of the three lignin samples have classified them as $p$-hydroxyphenyl/guaiacyl/ syringyl (HGS) lignins since KL and SL lignin samples comprised mainly of phenolic - $\mathrm{OH}$, while EOL comprised mainly of aliphatic - $\mathrm{OH}$ functional groups. High molecular weight of KL (as compared to SL and EOL) was influenced by the repolymerization reaction during the alkaline pulping process. The corrosion inhibition studies have revealed that the highest IE\% was obtained with SL, and this is in a good agreement with the antioxidant studies where SL also gave the highest OUI value compared to KL and EOL.

Acknowledgments The authors are grateful for the financial support of this research from CPER 2007-2013 "Structuration du Pôle de Compétitivité Fibres Grand'Est" and from Universiti Sains Malaysia through USM Research University Grant-1001/PKIMIA/854002. M. Hazwan Hussin would like to express his gratitude to the Ministry of High Education (MOHE) of Malaysia and Ministere Affaires Etrangeres de France for the MyPhD scholarship and Boursier du Governement Francais (CampusFrance). The EA 4370 LERMAB is supported by the French National Research Agency through the Laboratory of Excellence ARBRE (ANR-12-LABXARBRE-01)

\section{References}

Abdel-Gaber AM, Abd-El-Nabey BA, Sidahmed IM, El-Zayady AM, Saadawy M (2006) Inhibitive action of some plant extracts on the corrosion of steel in acidic media. Corros Sci 48:2765-2779. doi:10. 1016/j.corsci.2005.09.017
Ahamad I, Prasad R, Quraishi MA (2010) Adsorption and inhibitive properties of some new Mannich bases of Isatin derivatives on corrosion of mild steel in acidic media. Corros Sci 52:1472-1481. doi:10.1016/j.corsci.2010.01.015

Ammalahti E, Brunow G, Bardet M, Robert D, Kipelainen IJ (1998) Identification of side-chain structures in a poplar lignin using threedimensional HMQC-HOHAHA NMR spectroscopy. J Agr Food Chem 46:5113-5117. doi:10.1021/j9980249o

ASTM (1973) Standard method of salt spray (fog) testing. American Society of Testing and Materials. ASTM B 117-73:1-8

Benedeti AV, Sumodjo PTA, Nobe K, Cabot PL, Proud WG (1995) Electrochemical studies of copper, copper-aluminium and copperaluminium-silver alloys: impedance results in $0.5 \mathrm{M} \mathrm{NaCl}$. Electrochim Acta 40:2657-2668. doi:10.1016/0013-4686(95) 00108-Q

Bommersbach P, Alemany-Dumont C, Millet JP, Normand B (2005) Formation and behaviour study of an environment-friendly corrosion inhibitor by electrochemical methods. Electrochim Acta 51: 1076-1084. doi:10.1016/j.electacta.2005.06.001

Burton GW, Doba T, Gabe E, Hughes L, Lee FL, Prasad L, Ingold KU (1985) Autoxidation of biological molecules. 4. Maximizing the antioxidant activity of phenols. J Am Chem Soc 107:7035-7065. doi:10.1021/ja00310a049

El Hage R, Brosse N, Chrusciel L, Sanchez C, Sannigrahi P, Ragauskas A (2009) Characterization of milled wood lignin and ethanol organosolv lignin from Miscanthus. Polym Degrad Stabil 94: 1632-1638. doi:10.1016/j.polymdegradstab.2009.07.007

El Hage R, Chrusciel L, Desharnais L, Brosse N (2010) Effect of autohydrolysis of Miscanthus $\mathrm{x}$ giganteus on lignin structure and organosolv delignification. Bioresour Technol 101:9321-9329. doi: 10.1016/j.biortech.2010.06.143

El Hage R, Perrin D, Brosse N, (2012) Effect of pre-treatement severity on the antioxidant properties of ethanol organosolv Miscanthus $\mathrm{x}$ giganteus lignin. Nat Resour 3:29-34. doi: 10.4236/nr.2012.32005 DOI:10.4236/nr.2012.32005\# blank

El Oualja H, Perrin D, Martin R (1995) Kinetic study of the thermal oxidation of all-trans- $\beta$-carotene and evidence of its antioxygen properties. New J Chem 19:863-872

Garcia A, Toledano A, Serrano L, Egues I, Gonzales M, Marinn F, Labidi J (2009) Characterization of lignins obtained by selective precipitation. Sep Purif Technol 68:193-198. doi:10.1016/j.seppur.2009.05. 001

Garcia A, Toledano A, Andres MA, Labidi J (2010) Study of the antioxidant capacity of Miscanthus sinensis lignins. Process Biochem 45: 935-940. doi:10.1016/j.procbio.2010.02.015

Granata A, Argyropoulos DS (1995) 2-Chloro-4,4,5,5-tetramethyl-1,3,2dioxaphospholane, a reagent for the accurate determination of the uncondensed and condensed phenolic moieties in lignins. J Agric Food Chem 43:1538-1544. doi:10.1021/jf00054a023

Hussin MH, Kassim MJ (2011) The corrosion inhibition and adsorption behavior of Uncaria gambir extract on mild steel in $1 \mathrm{M} \mathrm{HCl}$. Mater Chem Phys 125:461-468. doi:10.1016/j.matchemphys.2010.10.032

Hussin MH, Rahim AA, Mohamad Ibrahim MN, Brosse N (2013) Physicochemical characterization of alkaline and ethanol organosolv lignins from oil palm (Elaeis guineensis) fronds as phenol substitutes for green material applications. Ind Crop Prod 49:23-32. doi:10.1016/j.indcrop.2013.04.030

Mohamad Ibrahim MN, Zakaria N, Sipaut CS, Sulaiman O, Hashim R (2011) Chemical and thermal properties of lignin from oil palm biomass as a substitute for phenol formaldehyde resin production. Carbohydr Polym 86:112-119. doi:10.1016/j.carbpol.2011.04.018

Obama P, Ricochon G, Munuglia L, Brosse N (2012) Combination of enzymatic hydrolysis and ethanol organosolv pretreatments: effect on lignin structures, delignification yields and cellulose-to-glucose conversion. Bioresour Technol 112:156-163. doi:10.1016/j. biortech.2012.02.080 
Pan XJ, Kadla JF, Ehara K, Gilkes N, Sadler JN (2006) Organosolv ethanol lignin from hybrid poplar as a radical scavenger: relationship between lignin structure extraction conditions and antioxidant activity. J Agric Food Chem 54:5806-5813. doi:10.1021/jf0605392

Poaty B, Dumarcay S, Gerardin P, Perrin D (2010) Modification of grape seed and wood tannis to lipophilic antioxidant derivatives. Ind Crop Prod 31:509-515. doi:10.1016/j. indcrop.2010.02.003

Pouteau C, Dole P, Cathala B, Averous L, Boquillon N (2003) Antioxidant properties of lignin in polypropylene. Polym Degrad Stabil 81:9-18. doi:10.1016/S0141-3910(03)00057-0

Saha JBT, Abia D, Dumarcay S, Ndikontar MK, Gerardin P, Noah JN, Perrin D (2013) Antioxidant activities, total phenolic contents and chemical compositions of extracts from four Cameroonian woods: padouk (Pterocarpus soyauxii Taubb), tali (Erythrophleum suaveolens), moabi (Baillonella toxisperma), and movingui (Distermonanthus benthamianus). Ind Crop Prod 41:71-77. doi: 10.1016/j.indcrop.2012.04.012

Sastri VS, Ghali E, Elboujdaini M (2007) Corrosion prevention and protection: practical solutions. John Wiley \& Sons Ltd, USA

She D, Xu F, Geng Z, Sun R, Jones GL, Baird MS (2010) Physicochemical characterization of extracted lignin from sweet sorghum stem. Ind Crop Prod 32:21-28. doi:10.1016/j.indcrop. 2010.02.00

Tejado A, Pena C, Labidi J, Echeverria JM, Mondragon II (2007) Physicochemical characterization of lignins from different sources for use in phenol-formaldehyde resin synthesis. Bioresour Technol 98:1655-1663. doi:10.1016/j.biortech.2006.05.042

Urgatondo V, Mitjans M, Vinardell MP (2009) Applicability of lignin from different sources as antioxidants based on the protective effects on lipid peroxidation induced by oxygen radicals. Ind Crop Prod 30: 184-187. doi:10.1016/j.indcrop.2009.03.001

Uri N (1961) Physico-chemical aspects of autoxidation. In: Lundberg WO (ed) Autoxidation and antioxidants. Inter-Science Publisher, New York, pp 55-106

Van de Klashorst GH (1989) Lignin-formaldehyde wood adhesives. In: Pizzi A (ed) Wood adhesives chemistry and technology. Marcel Dekker, New York, pp 155-190

Wanasundara UN, Shahidi F (1994) Stabilization of canola oil with flavonoid. Food Chem 50:393-396. doi:10.1016/0308-8146(94) 90211-9

Wanrosli WD, Zainuddin Z, Law KN, Asro R (2007) Pulp from oil palm fronds by chemical processes. Ind Crop Prod 25:89-94. doi:10. 1016/j.indcrop.2006.07.005 